\title{
PENGARUH JARAK TANAM PADA PENGGUNAAN METODE BUDIDAYA RAKIT TALI TERHADAP BERAT RUMPUT LAUT (Eucheuma cottonii) DI DUSUN TOISAPU KECAMATAN LEITIMUR SELATAN
}

\author{
Etnah Garpenassy ${ }^{1}, \mathrm{H}$. Tuaputty ${ }^{2}$ \\ ${ }^{1}$ Alumni Program Studi Pendidikan Biologi \\ ${ }^{2}$ Staf Pengajar Program Studi Pendidikan Biologi \\ E-mail: garpenase_etnah@gmail.com
}

\begin{abstract}
Background: Toisapu village is one of village in Ambon Island which have potential to develop seaweed. Prospects Seaweed cultivation is very beneficial if growth and quality can be developed as a base for the production of various purposes in the industrial world. However, cultivation techniques undertaken by the local community have not fully had good planting quality.

Method: The study includes the preparation phase, the implementation stage, and the observation stage. The parameters measured were the growth rate of Eucheuma cottonii seaweed is weight in the form of gram, using Completely Randomized Design (RAL) with 4 treatment levels and 6 replications.

Results: The results of this study show that at a distance of $30 \mathrm{~cm}$ seaweed growth experienced a better growth rate when compared with other growth spacing, with wet weight for 45 days was 218 grams.

Conclusion: Plant spacing affects the weight of seaweed, a good planting distance for seaweed growth is $30 \mathrm{~cm}$ at sea ebb and sea level with average wet weight for 45 days (6 weeks) is 218 grams.
\end{abstract}

Keywords: Planting Distance, Raft Raft Cultivation Method, Weight Seaweed (Eucheuma cottonii).

\begin{abstract}
Abstrak
Latar Belakang: Dusun Toisapu merupakan salah satu Dusun yang berada di Pulau Ambon yang potensial untuk mengembangkan rumput laut. Prospek Budidaya rumput laut sangat menguntungkan bila pertumbuhan dan kualitas dapat dikembangkan sebagai bahan dasar produksi berbagai keperluan dalam dunia industri. Namum teknik budidaya yang dilakukan oleh masyarakat setempat belum sepenuhnya memiliki kualitas tanam yang baik.

Metode: Penelitian meliputi tahap persiapan, tahap pelaksanaan, tahap pengamatan. Parameter yang diukur adalah tingkat pertumbuhan rumput laut eucheuma cottonii yaitu berat basah dalam bentuk gram, dengan menggunakan Rancangan Acak Lengkap (RAL) dengan 4 taraf perlakuan dan 6 kali ulangan.

Hasil: hasil penelitian ini menunjukan bahwa pada jarak $30 \mathrm{~cm}$ pertumbuhan rumput laut mengalami tingkat pertumbuhan yang lebih baik jika di bandingkan dengan jarak pertumbuhan yang lainnya, dengan berat basah selama 45 hari adalah 218 gram.

Kesimpulan: Jarak tanam mempengaruhi berat rumput laut, jarak tanam yang baik untuk pertumbuhan rumput laut adalah $30 \mathrm{~cm}$ pada surut tertinggi permukaan air laut dengan berat basah rata-rata selama 45 hari (6 minggu) adalah 218 gram.
\end{abstract}

Kata Kunci : Jarak Tanam, Metode Budidaya Rakit Tali, Berat Rumput Laut (Eucheuma cottonii). 


\section{PENDAHULUAN}

Propinsi Maluku adalah Propinsi yang terdiri dari 93,5\% luas perairan dan 6,5\% luas daratan. Sedangkan potensi garis pantai di Propinsi ini adalah 10,630 km. itu berarti sumber daya luas dan keanekaragamannya merupakan potensi yang cukup besar bagi pembangunan masyarakat Maluku. Hingga tumpuan pembangunan seyogyanya diarahkan untuk mengelola sumber daya yang ada di laut secara berkesinambungan (Nikijuluw, 1987). Dewasa ini perhatian terhadap biota laut semakin meningkat dengan munculnya kesadaran dan minat masyarakat akan pentingnya lautan. Menurut Bengen (2001), menjelaskan bahwa laut sebagai penyedia sumber daya alam yang produktif bak sumber pangan, tambang, mineral, energy, media komunikasi maupun kawasan rekreasi dan parawisata. Karena itu wilayah pesisir dan lautan merupakan tumpuan harapan manusia dalam pemenuhan kebutuhan hidup di masa datang.

Pulau Ambon dikenal sebagai salah satu Kota dengan gugusan pulau yang memberikan karakteristik khas sebagian besar wilayahnya terdiri dari pegunungan, perbukitan, pesisir pantai serta lautan. Karakteristik ini memberikan peluang adanya potensi yang dapat dimanfaatkan, diantaranya perairan Pulau Ambon yang memiliki sumber daya hayati laut beraneka ragam, mulai dari biota laut seperti berbagai jenis ikan, Gastropoda, Echinodermata, Molusca dan yang paling penting adalah lamun dan Rumput laut, yang merupakan sumber daya laut yang cukup potensial untuk dapat di manfaatkan terutama jenis rumput laut eucheuma cottonii sp.

Beberapa tempat di pulau Ambon yang telah berhasil dalam usaha budidaya rumput laut rumput diantaranya, perairan Desa Toisapu yang potensial untuk mengembangkan rumput laut karena kondisi lingkungnya yang mendukung dan substrat pasir berlumpur. Jenis rumput laut yang dibudidayakan di Dusun Toisapu adalah eucheuma cottonii, karena teknik budidayanya relative mudah dan fase pertumbuhanya sangat cepat karna di dukung oleh lingkungan yang mendukung.

\section{MATERI DAN METODE PENELITIAN Waktu Penelitian}

Penelitian ini berlangsung dari bulan Februari sampai dengan Maret 2014.

\section{Populasi dan Sampel}

Populasi dalam penelitian ini adalah rumput lut eucheuma cottnii yang ada di Dusun Toisapu yang di pilh secara Proposive Sampling. Dalam penelitian ini variabel yang dipakai terdiri atas variabel bebas yaitu jarak tanam antara $15 \mathrm{~cm}, 20$ $\mathrm{cm}, 25 \mathrm{~cm}$,dan $30 \mathrm{~cm}$, dan variabelterikat yaitu tingkat pertumbuhan rumput laut eucheuma cottonii (berat basah/ gram) yang di timbang perminggu selama 45 hari.

\section{Prosedur Penelitian}

Prosedur penelitian meliputi tahap persiapan, tahap pelaksanaan, tahap pengamatan. Dengan parameter yang diukur adalah tingkat pertumbuhan rumput laut eucheuma cottonii afah berat basah dalam bentuk gram, dengan menggunakan Rancangan Acak Lengkap (RAL) dengan 4 taraf perlakuan dn 6 kali ulangan. Teknik pengumpulan data berupa obserfasi pada lokasi penelitian dan dengan menggunakan kepustakaan.

\section{Teknik Analisis Data}

Data yang diperoleh dari penelitian ini dianalisis dengan menggunakan Uji $F$, sesuai dengan Rancangan Acak lengkap (RAL) Dengan 4 taraf perlakuan dan 6 kali ulangan. Apabila dalam perhitungan $\mathrm{F}>$ dari $F$ tabel maka akan dilakukan Uji lanjut dengan menggunakan Uji nyata terkecil (BNT) dengan menggunakau Rumus Uji BNT (Hanafih, 2002).

\section{HASIL DAN PEMBAHASAN Hasil Penelitian}

Hasil penelitian menunjukan bahwa, penggunaan tali utama terhadap peningkatan produktifitas Rumput Laut eucheuma cottonii dengan jarak tanam 15 $\mathrm{cm}, 20 \mathrm{c}, 25 \mathrm{~cm}$. $30 \mathrm{~cm}$ memberikan pengaruh yang sangat nyata. Pada perlakuan P1 (jarak $15 \mathrm{~cm}$ ), P2 (Jarak 20 $\mathrm{cm})$, P3 (jarak $25 \mathrm{~cm}$ ) dan P4 (jarak $30 \mathrm{~cm}$ ), berat rumpt laut Eucheuma cottonii mulamula adalah 100 gram dapat di lihat pada tabel 1 di bawah ini: 
Tabel 1. Laju Pertumbuhan Rumput Laut Eucheuma cottonii Selama Minggu Pengamatan (6 minggu).

\begin{tabular}{|c|c|c|c|c|c|c|c|}
\hline \multirow{3}{*}{ 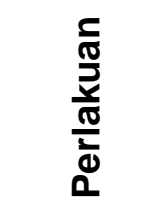 } & \multirow{3}{*}{$\begin{array}{l}\text { 옹 } \\
\text { 몰 }\end{array}$} & \multicolumn{6}{|c|}{ Berat rumput laut (gram) } \\
\hline & & \multicolumn{6}{|c|}{ Ulangan ke } \\
\hline & & 1 & 2 & 3 & 4 & 5 & 6 \\
\hline \multirow{7}{*}{$\begin{array}{c}A \\
(15 \mathrm{~cm})\end{array}$} & 0 & 100 & 100 & 100 & 100 & 100 & 100 \\
\hline & 1 & 120 & 120 & 125 & 125 & 125 & 120 \\
\hline & II & 135 & 150 & 135 & 145 & 140 & 175 \\
\hline & III & 165 & 185 & 170 & 165 & 170 & 185 \\
\hline & IV & 185 & 225 & 220 & 225 & 220 & 225 \\
\hline & V & 230 & 270 & 270 & 280 & 275 & 290 \\
\hline & VI & 300 & 300 & 320 & 345 & 320 & 340 \\
\hline \multirow{7}{*}{$\begin{array}{c}B \\
(20 \mathrm{~cm})\end{array}$} & 0 & 100 & 100 & 100 & 100 & 100 & 100 \\
\hline & 1 & 110 & 110 & 115 & 120 & 110 & 120 \\
\hline & II & 140 & 125 & 130 & 140 & 135 & 140 \\
\hline & III & 165 & 145 & 175 & 160 & 175 & 160 \\
\hline & IV & 190 & 185 & 195 & 190 & 195 & 190 \\
\hline & V & 230 & 245 & 240 & 230 & 240 & 245 \\
\hline & VI & 280 & 270 & 270 & 250 & 265 & 265 \\
\hline \multirow{7}{*}{$\begin{array}{c}\mathrm{C} \\
(25 \mathrm{~cm})\end{array}$} & 0 & 100 & 100 & 100 & 100 & 100 & 100 \\
\hline & 1 & 115 & 110 & 115 & 110 & 115 & 115 \\
\hline & II & 120 & 125 & 125 & 130 & 130 & 130 \\
\hline & III & 140 & 135 & 135 & 140 & 145 & 145 \\
\hline & IV & 180 & 170 & 175 & 180 & 185 & 180 \\
\hline & V & 210 & 200 & 205 & 200 & 210 & 210 \\
\hline & VI & 245 & 240 & 240 & 240 & 245 & 245 \\
\hline \multirow{7}{*}{$\begin{array}{c}D \\
(30 \mathrm{~cm})\end{array}$} & 0 & 120 & 125 & 125 & 130 & 130 & 130 \\
\hline & 1 & 110 & 110 & 115 & 110 & 115 & 115 \\
\hline & II & 135 & 135 & 140 & 135 & 140 & 140 \\
\hline & III & 170 & 170 & 165 & 170 & 165 & 165 \\
\hline & IV & 205 & 210 & 205 & 210 & 205 & 210 \\
\hline & V & 250 & 265 & 250 & 265 & 250 & 365 \\
\hline & VI & 305 & 310 & 310 & 315 & 310 & 305 \\
\hline
\end{tabular}

Metode Budidaya yang dipakai sangat berpengaruh terhadap pertmbuhan rumput laut. Metode yang dipakai dalam penelitian ini adalah Metode rakit tali, karena menurut masyarakat setempat Metode ini sangat efisien dan baik karna dapat menghemat tempat serta menghemat biaya, Karena mengingat tempat pembudidayaannya berada pada lokasi yang curam. Metode Rakit Tali adalah gabungan dua metode budidaya yang di gabungkan menjadi satu Metode Budidaya yaitu Metode Long Line dan Metode Rakit Apung. Hasil yang di peroleh dari tiap-tiap perlakuan terdapat perbedan, dimana pada jarak perlakuan P4 (Jarak tanam $30 \mathrm{~cm}$ ) menunjukan hasil yang optimal yaitu pada minggu panen selama 6 minggu berat rata-rata Rumput Laut eucheuma cottoni adalah 52 gram dibandingkan dengan P1 (jarak $15 \mathrm{~cm}$ ) berat rata-rata eucheuma cttonii adalah 51 gram, P2 (Jarak $20 \mathrm{~cm}$ ) dan berat rata-rata eucheuma cottonii adalah 28 gram, dan P3 (Jarak tanam $25 \mathrm{~cm}$ ) berat eucheuma cottonii adalah 37 gram dapat dilihat pada tabel 2 sampai 5 di bawah ini: 
Tabel 2. Data Hasil Pengamatan Pertumbuhan Rumput Laut Eucheuma cottonii (gram) yang ditanam pada jarak $15 \mathrm{~cm}(\mathrm{~A})$.

\begin{tabular}{|c|c|c|c|c|c|c|c|c|}
\hline \multirow{3}{*}{ Minggu } & \multicolumn{6}{|c|}{ Berat rumput laut (gram) } & \multirow{3}{*}{$\frac{\frac{c}{\pi}}{\frac{\pi}{E}}$} & \multirow{3}{*}{$\begin{array}{l}\frac{\pi}{\pi} \\
\frac{\pi}{\pi} \\
\mathbb{\pi} \\
\mathbb{\pi}\end{array}$} \\
\hline & \multicolumn{6}{|c|}{ Ulangan ke } & & \\
\hline & 1 & 2 & 3 & 4 & 5 & 6 & & \\
\hline I & 20 & 20 & 25 & 25 & 25 & 20 & 135 & 23 \\
\hline II & 15 & 30 & 10 & 20 & 15 & 55 & 145 & 24 \\
\hline III & 30 & 30 & 35 & 20 & 30 & 10 & 155 & 26 \\
\hline IV & 20 & 40 & 50 & 60 & 50 & 40 & 260 & 43 \\
\hline V & 45 & 45 & 45 & 50 & 55 & 65 & 305 & 51 \\
\hline VI & 60 & 35 & 50 & 65 & 45 & 50 & 305 & 51 \\
\hline Jumlah & 190 & 200 & 215 & 240 & 220 & 240 & 1305 & 218 \\
\hline Rata-rata & 32 & 33 & 36 & 40 & 37 & 40 & 218 & 36 \\
\hline
\end{tabular}

Tabel diatas menunjukan bahwa jumlah keseluruhan berat selama minggu pengamatan (1-6 minggu) adalah 1305 dengan rata-rata 218 gram.

Tabel 3. Data Hasil Pengamatan Pertumbuhan Rumput Laut Eucheuma cottonii (gram) yang ditanam pada jarak $20 \mathrm{~cm}(B)$.

\begin{tabular}{|c|c|c|c|c|c|c|c|c|}
\hline \multirow{3}{*}{ Minggu } & \multicolumn{6}{|c|}{ Berat rumput laut (gram) } & \multirow{3}{*}{$\frac{\frac{\sigma}{\pi}}{\frac{\Xi}{丂}}$} & \multirow{3}{*}{$\begin{array}{l}\frac{\pi}{\pi} \\
\frac{\pi}{\pi} \\
\frac{\pi}{\pi}\end{array}$} \\
\hline & \multicolumn{6}{|c|}{ Ulangan ke } & & \\
\hline & 1 & 2 & 3 & 4 & 5 & 6 & & \\
\hline I & 10 & 10 & 15 & 20 & 10 & 20 & 85 & 14 \\
\hline II & 30 & 15 & 15 & 20 & 25 & 20 & 125 & 21 \\
\hline III & 25 & 20 & 45 & 20 & 40 & 20 & 170 & 28 \\
\hline IV & 25 & 40 & 20 & 30 & 20 & 30 & 165 & 28 \\
\hline V & 40 & 55 & 45 & 40 & 45 & 55 & 280 & 47 \\
\hline VI & 50 & 25 & 30 & 20 & 25 & 20 & 170 & 28 \\
\hline Jumlah & 180 & 165 & 170 & 150 & 165 & 165 & 995 & 166 \\
\hline Rata-rata & 30 & 28 & 28 & 25 & 28 & 28 & 166 & 28 \\
\hline
\end{tabular}

Tabel di atas menunjukan bahwa jumlah keseluruhan berat selama minggu pengamatan (1-6 minggu) adalah 995 dengan rata-rata 166 gram. 
Tabel 4. Data Hasil Pengamatan Pertumbuhan Rumput Laut Eucheuma Cottonii (gram) yang ditanam pada jarak $25 \mathrm{~cm}$ (C).

\begin{tabular}{|c|c|c|c|c|c|c|c|c|}
\hline \multirow{3}{*}{ Minggu } & \multicolumn{6}{|c|}{ Berat rumput laut (gram) } & \multirow{3}{*}{$\frac{\frac{c}{\pi}}{\frac{E}{3}}$} & \multirow{3}{*}{$\begin{array}{l}\frac{\pi}{\pi} \\
\frac{1}{\pi} \\
\frac{\pi}{\pi} \\
\mathbb{\pi}\end{array}$} \\
\hline & \multicolumn{6}{|c|}{ Ulangan ke } & & \\
\hline & 1 & 2 & 3 & 4 & 5 & 6 & & \\
\hline I & 15 & 10 & 15 & 10 & 15 & 15 & 80 & 13 \\
\hline II & 10 & 15 & 10 & 20 & 15 & 15 & 85 & 14 \\
\hline III & 15 & 10 & 10 & 10 & 15 & 15 & 75 & 13 \\
\hline IV & 40 & 45 & 40 & 40 & 35 & 35 & 235 & 39 \\
\hline V & 30 & 25 & 30 & 20 & 25 & 20 & 150 & 25 \\
\hline VI & 35 & 40 & 35 & 40 & 35 & 35 & 220 & 37 \\
\hline Jumlah & 145 & 145 & 140 & 140 & 140 & 135 & 845 & 141 \\
\hline Rata-rata & 24 & 24 & 23 & 23 & 23 & 23 & 141 & 23 \\
\hline
\end{tabular}

Tabel diatas menunjukan bahwa jumlah keseluruhan berat selama minggu pengamatan (1-6 minggu) adalah 845 dengan rata-rata 141 gram.

Tabel 5. Data Hasil Pengamatan Pertumbuhan Rumput Laut Eucheuma cottonii (gram) yang ditanam pada jarak $30 \mathrm{~cm}$ (D).

\begin{tabular}{|c|c|c|c|c|c|c|c|c|}
\hline \multirow{3}{*}{ Minggu } & \multicolumn{6}{|c|}{ Berat rumput laut (gram) } & \multirow{3}{*}{$\frac{\frac{c}{\sqrt{0}}}{\frac{E}{3}}$} & \multirow{3}{*}{$\begin{array}{l}\frac{\pi}{\pi} \\
\frac{\pi}{\pi} \\
\frac{\pi}{\pi} \\
\mathbb{\pi}\end{array}$} \\
\hline & \multicolumn{6}{|c|}{ Ulangan ke } & & \\
\hline & 1 & 2 & 3 & 4 & 5 & 6 & & \\
\hline 1 & 10 & 15 & 10 & 15 & 15 & 15 & 80 & 13 \\
\hline II & 15 & 15 & 25 & 25 & 25 & 25 & 130 & 22 \\
\hline III & 35 & 35 & 25 & 35 & 25 & 25 & 180 & 30 \\
\hline IV & 35 & 40 & 40 & 40 & 40 & 45 & 240 & 40 \\
\hline V & 45 & 55 & 45 & 55 & 45 & 55 & 300 & 50 \\
\hline VI & 55 & 45 & 60 & 50 & 60 & 40 & 310 & 52 \\
\hline Jumlah & 195 & 205 & 205 & 220 & 210 & 205 & 1240 & 207 \\
\hline Rata-rata & 33 & 34 & 34 & 37 & 35 & 34 & 207 & 34 \\
\hline
\end{tabular}

\section{KESIMPULAN DAN SARAN}

Berdasarkan hasil penelitian dan analisis yang telah dilakukan maka dapat disimpulkan bahwa jarak tamam mempengaruhi berat rumput laut, jarak tanam yang baik untuk pertumbuhan rumput laut adalah $30 \mathrm{~cm}$ pada surut tertinggi permukaan air laut dengan berat basah rata- rata selama 45 hari (6 minggu) adalah 218 gram.

\section{DAFTAR PUSTAKA}

Bengen, DG. 2001. Pengelolaan wilayah pesisir secara terpadu berkelanjutan dan berbasis masyarakat (Makalah) di dalam: Pelatihan penyuluhan wilayah pesisir secara terpadu.Makasar, 4-9 Maret 2001.

Hanafiah, A.K. 2002. Rancangan percobaan dan teori Aplikasi edisi ke 
tiga. Jakarta: PT. Raja Grafindo Persada.

Nikijuluw, V. Abrahams. James.1997. Perikanan dan kelautan Maluku. Ambon: Dinas Perikanan dan Kelautan Propinsi Maluku.

Ruslaini, 2013. Pengaruh jarak tanam terhadap pertumbuhan dan kandungan keragenan Rumput Laut (eucheuma spinosum) menggunakan Metode Long line. Jurnal Mina laut Indonesia Vol 03.No, 12. 113-123.

Wa Surni. 2012. Pertumbuhan Rumput Laut (Eucheuma cottonii) pada kedalaman Air Laut yang berbeda di Dusun Kotanian Desa Eti Kecamatan Seram Bagian Barat. Skripsi Tidak dipublikasikan. FKIP Biologi. Universitas Pattimura Ambon. $64 \mathrm{Hal}$. 